\title{
Presynchronization with Double-Ovsynch improves fertility at first postpartum artificial insemination in lactating dairy cows
}

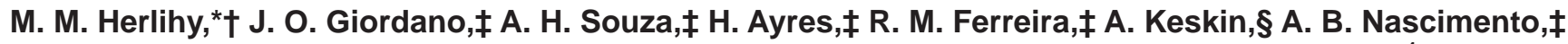 \\ J. N. Guenther,‡ J. M. Gaska,\# S. J. Kacuba,II M. A. Crowe,†ף S. T. Butler, ${ }^{*}$ and M. C. Wiltbank ${ }^{1}$ \\ *Teagasc, Animal and Grassland Research and Innovation Centre, Moorepark, Fermoy, Co. Cork, Ireland \\ †UCD School of Veterinary Medicine, University College Dublin, Belfield, Dublin 4, Ireland \\ ¥Department of Dairy Science, University of Wisconsin, 1675 Observatory Drive, Madison 53706 \\ $\S$ Department of Obstetrics and Gynecology, Faculty of Veterinary Medicine, University of Uludag, Bursa, Turkey 16059 \\ \#Gaska Dairy Health Services, W11366 Behan Road, Columbus, WI 53925 \\ \|Select Sires, N6550 Hwy 151, Beaver Dam, WI 53916 \\ qUCD Conway Institute of Biomolecular and Biomedical Research, University College Dublin, Belfield, Dublin 4, Ireland
}

\begin{abstract}
The objective of this study was to compare circulating progesterone $(\mathrm{P} 4)$ profiles and pregnancies per $\mathrm{AI}$ $(\mathrm{P} / \mathrm{AI})$ in lactating dairy cows bred by timed artificial insemination (TAI) following Ovsynch-56 after 2 different presynchronization protocols: Double-Ovsynch (DO) or Presynch-Ovsynch (PS). Our main hypothesis was that DO would increase fertility in primiparous cows, but not in multiparous cows. Within each herd $(\mathrm{n}=3)$, lactating dairy cows $(\mathrm{n}=1,687 ; 778$ primiparous, 909 multiparous) were randomly assigned to DO $\left[\mathrm{n}=837\right.$; GnRH-7d-PGF ${ }_{2 \alpha}-3 \mathrm{~d}-$ GnRH-7d-Ovsynch-56 (GnRH-7d-PGF $\left.\left.2_{2 \alpha}-56 \mathrm{~h}-\mathrm{GnRH}-16 \mathrm{hTAI}\right)\right]$ or PS ( $=$ 850; $\mathrm{PGF}_{2 \alpha}-14 \mathrm{~d}-\mathrm{PGF}_{2 \alpha}-12 \mathrm{~d}-$-Ovsynch-56). In 1 herd, concentrations of $\mathrm{P} 4$ were determined at the first $\mathrm{GnRH}$ (GnRH1) of Ovsynch-56 and at d 11 after TAI ( $\mathrm{n}=$ 739). In all herds, pregnancy was diagnosed by palpation per rectum at $39 \mathrm{~d}$. In 1 herd, the incidence of late embryo loss was determined at $74 \mathrm{~d}$, and data were available on $\mathrm{P} / \mathrm{AI}$ at the subsequent second service. Presynchronization with DO reduced the percentage of animals with low $\mathrm{P} 4$ concentrations $(<0.50 \mathrm{ng} / \mathrm{mL})$ at GnRH1 of Ovsynch-56 (5.4 vs. $25.3 \%$, DO vs. PS). A lesser percentage of both primiparous and multiparous cows treated with DO had low P4 concentrations at GnRH1 of Ovsynch-56 (3.3 vs. 19.7\%, DO vs. PS primiparous; and 8.8 vs. $31.9 \%$, DO vs. PS multiparous). Presynchronization with $\mathrm{DO}$ improved $\mathrm{P} / \mathrm{AI}$ at the first postpartum service (46.3 vs. $38.2 \%$, DO vs. PS). Statistically, a fertility improvement could be detected for primiparous cows treated with DO (52.5 vs. $42.3 \%$, DO vs. PS, primiparous), but only a tendency could be detected in multiparous cows (40.3 vs. $34.3 \%$, DO
\end{abstract}

\footnotetext{
Received December 13, 2011.

Accepted June 16, 2012.

${ }^{1}$ Corresponding author: wiltbank@wisc.edu
}

vs. PS, multiparous), consistent with our original hypothesis. Presynchronization treatment had no effect on the incidence of late embryo loss after first service (8.5 vs. $5.5 \%$, DO vs. PS). A lower body condition score increased the percentage of cows with low $\mathrm{P} 4$ at GnRH1 of Ovsynch-56 and reduced fertility to the TAI. In addition, P4 concentration at d 11 after TAI was reduced by DO. The method of presynchronization at first service had no effect on $\mathrm{P} / \mathrm{AI}$ at the subsequent second service (34.7 vs. $36.5 \%$, DO vs. PS). Thus, presynchronization with DO induced cyclicity in most anovular cows and improved fertility compared with PS, suggesting that DO could be a useful reproductive management protocol for synchronizing first service in commercial dairy herds.

Key words: presynchronization, Ovsynch, dairy cow, pregnancy rate

\section{INTRODUCTION}

Reproductive efficiency in lactating dairy cows is not optimal, encouraging the development of several different reproductive management strategies focused on improving the use of AI and pregnancy rates in dairy herds (Thatcher et al., 2006). One of the most common strategies is Ovsynch (Pursley et al., 1995), in which GnRH and $\mathrm{PGF}_{2 \alpha}$ are combined to synchronize the time of ovulation, allowing timed AI (TAI). The Ovsynch-56 protocol specifically includes an injection of GnRH $7 \mathrm{~d}$ before and $56 \mathrm{~h}$ after an injection of $\mathrm{PGF}_{2 \alpha}$ (Brusveen et al., 2008), resulting in ovulation 24 to $32 \mathrm{~h}$ after GnRH (Pursley et al., 1995), with the highest fertility (pregnancies per AI; $\mathbf{P} / \mathbf{A I}$ ) achieved when TAI is completed $16 \mathrm{~h}$ after the second GnRH treatment (Pursley et al., 1998). It is interesting that when Ovsynch was initiated on d 1 to 4 of the estrous cycle, ovulation rates as low as $23 \%$ were observed because of the lower ovulatory capacity of follicles early in the estrous cycle. 
Conversely, when Ovsynch was initiated on d 5 to 9 of the estrous cycle, GnRH-induced ovulatory responses were increased to 85 to $96 \%$ (Vasconcelos et al., 1999; Bello et al., 2006). Greater ovulatory responses to the first GnRH (GnRH1) of Ovsynch have been shown to positively affect synchronization and $\mathrm{P} / \mathrm{AI}$ in lactating dairy cows (Vasconcelos et al., 1999; Galvão and Santos, 2010). Thus, presynchronization of ovarian function before Ovsynch could improve fertility to the TAI.

Based on this idea, protocols have been developed to presynchronize cows before Ovsynch that traditionally use 2 injections of $\mathrm{PGF}_{2 \alpha}$ administered $14 \mathrm{~d}$ apart with initiation of the TAI protocol 11 d (Galvão et al., 2007), $12 \mathrm{~d}$ (Moreira et al., 2001), or $14 \mathrm{~d}$ (Navanukraw et al., 2004) later. These protocols have been termed Presynch-Ovsynch (PS) and have been found to increase $\mathrm{P} / \mathrm{AI}$ compared with Ovsynch in cyclic cows (Moreira et al., 2001) or in all cows (Navanukraw et al., 2004; Galvão et al., 2007). Earlier studies that used 2 injections of $\mathrm{PGF}_{2 \alpha}$ to presynchronize estrous cycles recognized that this approach was not effective for anovular cows (Moreira et al., 2001). Gümen et al. (2003) reported that a high percentage of anovular cows ovulated to GnRH1 of Ovsynch albeit dependent on the stage of the follicular wave at the time of this $\mathrm{GnRH}$ injection. However, anovular cows still had greatly reduced fertility to the TAI protocol. Thus, strategies that induce production of a corpus luteum (CL) before initiation of the Ovsynch protocol are likely to improve fertility in anovular cows.

One strategy that has been reported to induce cyclicity in anovular dairy cows is the use of an Ovsynch protocol to presynchronize and induce cyclicity in cows before the use of a breeding Ovsynch protocol, termed Double-Ovsynch (DO; Souza et al., 2008; Wiltbank et al., 2011b). A field study (Souza et al., 2008) comparing the standard $\mathrm{PGF}_{2 \alpha}$-based PS with DO showed improved $\mathrm{P} / \mathrm{AI}$ in cows receiving the DO strategy. However, the experiment was not large $(\mathrm{n}=337)$, and unexpectedly, improvements were limited to primiparous cows and were not observed in multiparous cows. Although these results suggested that DO could be a good alternative for presynchronization of lactating dairy cows, further trials using larger numbers of experimental units were required to confirm these preliminary findings. Thus, our primary hypothesis for this study was that DO would improve fertility compared with the PS protocol for first-service TAI, particularly in primiparous cows. A second hypothesis was that DO would increase the percentage of cows that were cycling at the initiation of Ovsynch. In addition, the effect of presynchronization strategy on circulating concentrations of P4 on d 11 after TAI, and fertility at the subsequent AI were tested.

\section{MATERIALS AND METHODS}

\section{Farms and Animals}

This experiment was performed on 3 commercial farms in south-central Wisconsin from March 2007 to April 2010. Lactating dairy cows $(\mathrm{n}=1,687 ; 778$ primiparous, 909 multiparous) were housed in free-stall facilities bedded with sand and equipped with feedline head lockup gates, and had ad libitum access to fresh feed and water. Diets were typical for Wisconsin, using corn silage as the major forage and balanced by a professional nutritional consultant for protein, vitamins, and minerals. A similar experimental protocol was used on all 3 farms. Fertility evaluations were performed on all 3 farms, and additional ultrasound evaluations of the ovaries and measurement of circulating progesterone (P4) were completed on 1 farm. On the farm with physiological measurements, 739 lactating Holstein cows (398 multiparous, 341 primiparous) were enrolled in the study. All cows received bST (Posilac, $500 \mathrm{mg}$ / dose; Monsanto Co., St. Louis, MO) starting at 57 to $68 \mathrm{~d}$ postpartum and continuing every $11 \mathrm{~d}$ throughout the study. Cows were milked 3 times daily and fed a TMR twice daily that consisted of corn silage and alfalfa silage as forage with a corn- and soybean meal-based concentrate. The TMR was balanced to meet or exceed minimum nutritional requirements for dairy cows (NRC, 2001). Lists for scheduled injections (completed by AI personnel) and pregnancy examination (completed by the herd veterinarian) for individual cows were generated weekly using a commercial on-farm software program (Dairy Comp 305; Valley Agricultural Software, Tulare, CA). This program was also used to track and record reproductive outcomes, individual cow events, and milk production records for each cow enrolled in the experiment. All animal procedures were approved by the Animal Care Committee of the College of Agriculture and Life Sciences, University of Wisconsin, and were conducted while cows were restrained in the feedline lockup gates.

\section{Presynchronization Treatments and Al}

Cohorts of cows on a weekly basis were randomly assigned to 1 of 2 hormonal protocols to facilitate first postpartum TAI, either PS or DO. Double-Ovsynch uses an Ovsynch protocol for presynchronization, followed by the Ovsynch-56 protocol $7 \mathrm{~d}$ later to facilitate TAI (Brusveen et al., 2008). Presynch-Ovsynch uses 2 injections of $\mathrm{PGF}_{2 \alpha}$ administered $14 \mathrm{~d}$ apart for presynchronization, followed by the Ovsynch- 56 protocol 12 d later to facilitate TAI. Animals were assigned 
to treatments based on animal identification number; odd-numbered cows were assigned to PS, and evennumbered cows were assigned to DO. As illustrated in Figure 1 , animals assigned to PS $(\mathrm{n}=850)$ received 2 injections of $\mathrm{PGF}_{2 \alpha}$ (35 $\mathrm{mg}$ of dinoprost tromethamine; Vedco Inc., St. Joseph, MO) at $45 \pm 3$ DIM and $59 \pm 3$ DIM, and then began the Ovsynch-56 TAI protocol 12 $\mathrm{d}$ later. Animals detected in estrus between the second $\mathrm{PGF}_{2 \alpha}$ of PS and GnRH1 of Ovsynch-56 were not inseminated. As illustrated in Figure 1, animals assigned to DO $(\mathrm{n}=837)$ received GnRH $(100 \mu \mathrm{g}$ of gonadorelin diacetate tetrahydrate; Vedco Inc.) at $54 \pm 3$ DIM, followed by an injection of $\mathrm{PGF}_{2 \alpha} 7 \mathrm{~d}$ later and $\mathrm{GnRH}$ $72 \mathrm{~h}$ after $\mathrm{PGF}_{2 \alpha}$, and then began the Ovsynch-56 TAI protocol $7 \mathrm{~d}$ later. All cows received the Ovsynch-56 TAI protocol: GnRH at $71 \pm 3$ DIM, $\mathrm{PGF}_{2 \alpha} 7 \mathrm{~d}$ later, GnRH $56 \mathrm{~h}$ after $\mathrm{PGF}_{2 \alpha}$, and TAI 12 to $14 \mathrm{~h}$ later at 81 \pm 3 DIM (Figure 1). On each farm, a single professional AI technician performed all inseminations, with multiple sires equally balanced between the 2 experimental treatments.

\section{Transrectal Ultrasonography}

On the farm with physiological measurements, transrectal ultrasonography was performed using an ultrasound scanner fitted with a $7.5-\mathrm{MHz}$ linear-array transducer (Easi-Scan portable; BCF Technology Ltd., Livingston, UK) at $92 \pm 3$ DIM, coinciding with d 11 after TAI, to determine the presence or absence of a CL. Corpora lutea were counted and recorded for each ovary. The diameter of the visualized CL was estimated by using an image of the apparent maximal diameter of the structure, using on-screen background gridlines of 10-mm squares. Luteal volume was calculated as $\mathrm{V}$ $=4 / 3 \times \pi \times \mathrm{r}^{3}$, where the radius (r) was calculated as $0.5 \times$ CL diameter. For CL with a fluid-filled cavity, the volume of the cavity was calculated and subtracted from the total CL volume. Transrectal ultrasonography was not performed on animals enrolled in wk 1 of the experiment $(\mathrm{n}=35)$. Thus, on the farm with physiological measurements, of the 739 animals enrolled in the study, 688 animals underwent transrectal ultrasound examination on d 11 after TAI.

\section{Pregnancy Diagnosis}

After the first postpartum TAI, pregnancy was diagnosed on each of the 3 farms by palpation per rectum of the uterus at $39 \mathrm{~d}$. On the farm with physiological measurements, pregnant cows were reexamined by palpation per rectum at $74 \mathrm{~d}$ after TAI. One week before pregnancy diagnosis (d 32), all cows were administered GnRH and were enrolled in the Ovsynch-56 TAI protocol for resynchronization and reinsemination (d 32 Resynch; Silva et al., 2009). On the day of nonpregnancy diagnosis, cows that had not been reinseminated were administered $\mathrm{PGF}_{2 \alpha}$ and completed the d 32 Resynch protocol. Cows reinseminated before being examined for pregnancy diagnosis were considered not pregnant to the previous TAI.

\section{Blood Collection and P4 RIA}

On the farm with physiological measurements, blood samples for serum $\mathrm{P} 4$ analysis were collected via puncture of the median caudal vein or artery into evacuated tubes (Vacutainer; Becton Dickinson, Franklin Lakes, NJ) at $71 \pm 3$ DIM and $92 \pm 3$ DIM coinciding with GnRH1 of Ovsynch-56 and d 11 after TAI, respectively, to determine $\mathrm{P} 4$ concentrations at these times. Blood samples were transported to the laboratory and centrifuged at $3,000 \times g$ for $20 \mathrm{~min}$ at $4^{\circ} \mathrm{C}$. Serum was harvested and decanted into $1.5-\mathrm{mL}$ micro tubes, sealed
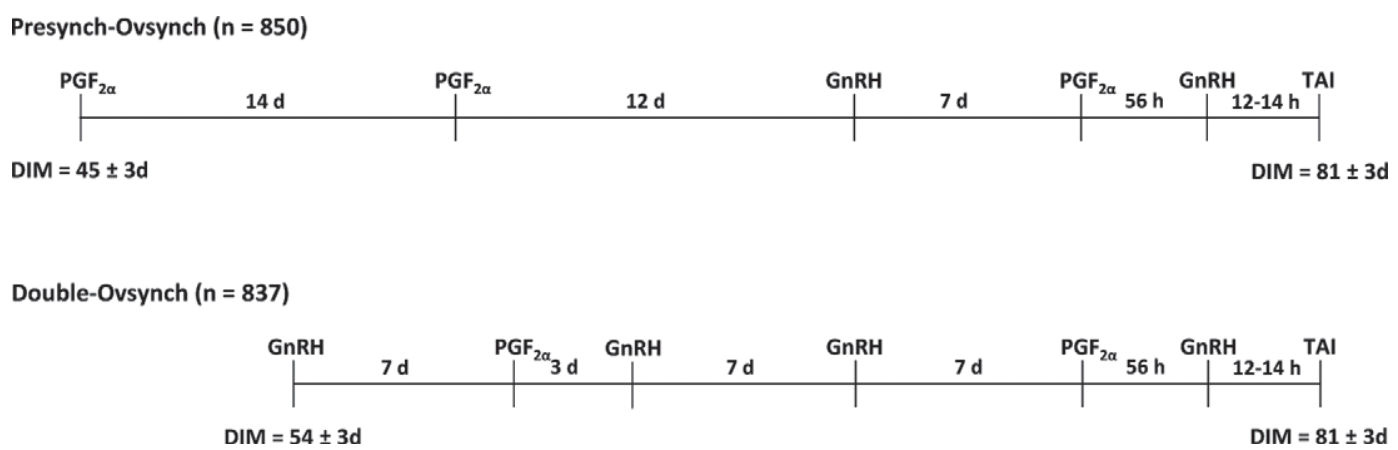

Figure 1. Schematic diagram of hormonal treatments in lactating dairy cows (mean \pm range of DIM). Animals assigned to PresynchOvsynch received 2 injections of $\mathrm{PGF}_{2 \alpha}$ at $45 \pm 3$ DIM and $59 \pm 3$ DIM and then began the Ovsynch-56 timed AI (TAI) protocol $12 \mathrm{~d}$ later. Animals assigned to Double-Ovsynch received $\mathrm{GnRH}$ at $54 \pm 3 \mathrm{DIM}$, followed by an injection of $\mathrm{PGF}_{2 \alpha} 7 \mathrm{~d}$ later, GnRH $72 \mathrm{~h}$ after PGF $\mathrm{F}_{2 \alpha}$, and then began the Ovsynch-56 TAI protocol $7 \mathrm{~d}$ later. All cows received the Ovsynch-56 TAI protocol: GnRH at $71 \pm 3$ DIM, PGF $7 \alpha \mathrm{d}$ later, GnRH $56 \mathrm{~h}$ after $\mathrm{PGF}_{2 \alpha}$, and TAI 12 to $14 \mathrm{~h}$ later at $81 \pm 3$ DIM. 
with an airtight cap, and stored at $-20^{\circ} \mathrm{C}$ until later analysis. Concentrations of $\mathrm{P} 4$ in serum were determined by using a commercially available solid-phase RIA (Coat-A-Count Progesterone; Diagnostic Products Corporation, Los Angeles, CA). The mean inter- and intraassay CV were 2.43 and $4.12 \%$, respectively, using a quality control sample with $2.50 \mathrm{ng} / \mathrm{mL}$ of $\mathrm{P} 4$. On the farm with physiological measurements, all 739 animals enrolled in the study had serum $\mathrm{P} 4$ determined at GnRH1 of Ovsynch-56, and 728 animals had serum P4 determined on d 11 after TAI. The frequency distribution of cows according to circulating P4 concentrations at GnRH1 of Ovsynch-56 and d 11 after TAI was determined using increments of $0.50 \mathrm{ng} / \mathrm{mL}$. To examine $\mathrm{P} / \mathrm{AI}$ at first postpartum service for cows with low, medium, and high $\mathrm{P} 4$ concentrations at GnRH1 of Ovsynch-56, cows were classified according to $\mathrm{P} 4$ at $71 \pm 3$ DIM as follows: low $(<0.50 \mathrm{ng} / \mathrm{mL})$, medium $(\geq 0.50$ to $\leq 3.00 \mathrm{ng} / \mathrm{mL})$, and high $(>3.00 \mathrm{ng} / \mathrm{mL})$. To examine $\mathrm{P} / \mathrm{AI}$ at first postpartum service for cows with low, medium, and high $\mathrm{P} 4$ concentrations on d 11 after TAI, cows were classified according to $\mathrm{P} 4$ at $92 \pm 3$ DIM as follows: low $(<2.00 \mathrm{ng} / \mathrm{mL})$, medium1 $(\geq 2.00$ to $<3.50 \mathrm{ng} / \mathrm{mL})$, medium2 $(\geq 3.50$ to $\leq 5.00 \mathrm{ng} / \mathrm{mL})$, and high $(>5.00 \mathrm{ng} / \mathrm{mL})$.

\section{$B C S$}

Cows were evaluated for BCS at $92 \pm 3$ DIM, coinciding with d 11 after TAI on a 1 to 5 scale $(1=$ emaciated and $5=$ extremely fat) in increments of 0.25, as outlined by Edmonson et al. (1989). Cows were classified according to BCS at $92 \pm 3$ DIM as $\leq 2.50$ (low) or $>2.50$ (high). On the farm with physiological measurements, BCS was not recorded for animals enrolled in wk 1 and $2(\mathrm{n}=74)$, and 9 animals missed BCS evaluation on d 11 after TAI. Thus, on the farm with physiological measurements, of the 739 animals enrolled in the study, 656 animals had BCS evaluated on d 11 after TAI.

\section{Compliance with the Protocol}

On the farm with physiological measurements, cows that died or were culled during the study $(\mathrm{n}=16)$, and cows that were bred before $(n=13)$ or after $(n=2)$ the scheduled TAI date were removed from the data set. Thus, after data edits, the final data set on the farm with physiological measurements included 739 cows; the numbers of animals reported per treatment were as follows: PS $(\mathrm{n}=373)$ and DO $(\mathrm{n}=366)$. On the other 2 farms, cows that died or were culled during the study $(\mathrm{n}=90)$, and cows that missed injections or cows that were not bred according to the TAI protocol $(\mathrm{n}=$
146) were removed from the data set. Thus, after data edits, the final data included 1,687 cows; the numbers of animals reported per treatment were as follows: PS $(\mathrm{n}=850)$ and DO $(\mathrm{n}=837)$.

\section{Statistical Analysis}

All statistical analyses were completed using SAS software (SAS Institute, 2006). Variables with a binomial distribution, such as $\mathrm{P} / \mathrm{AI}$ at first and second $\mathrm{AI}$ and embryonic loss, were analyzed by logistic regression using the GLIMMIX procedure, with cow included as a random effect. The adjusted $\mathrm{P} / \mathrm{AI}$ values provided by SAS are given throughout the text. Because DO was expected to increase P/AI compared with PS (Souza et al., 2008; Wiltbank et al., 2011b), a one-tailed comparison was used throughout the experiment for this comparison. The unadjusted values and actual experimental units (number pregnant divided by number inseminated) are also provided in each of the tables.

Continuous variables were also analyzed using the GLIMMIX procedure. An appropriate distribution was specified for each response variable in the model. The models included the fixed effects of treatment (DO or PS), parity (class $=1, \geq 2)$, BCS $[$ class $=$ low $(\leq 2.50)$ or high $(>2.50)$ ], week/replicate (class), farm (class), and average daily milk production from $7 \mathrm{~d}$ before AI (continuous). Biologically plausible interactions were tested for significance in the model for each dependent variable. Final models were chosen based on the least Akaike's information criterion. Because previous research had demonstrated that DO was more effective in primiparous than multiparous cows (Souza et al., 2008), preplanned contrasts were used to compare treatment effects within parity. Differences between least squares means were compared using the Tukey option to adjust for multiple comparisons. Differences between treatments were declared significant when $P \leq$ 0.05 , and a tendency toward significance was assumed when $0.05<P \leq 0.10$. The proportion of cows in each $\mathrm{P} 4$ classification group was analyzed using the events/ trials function of the LOGISTIC procedure. The determination that physiological measurements would be performed on only a subset of cows was based on the idea that the $\mathrm{P} 4$ concentrations would be primarily used to evaluate the second hypothesis that DO would increase the percentage of cows that were cycling at the start of the protocol. A $20 \%$ anovular to $10 \%$ anovular value could be detected at $\alpha=0.05$, with $98 \%$ power when using 350 cows per treatment group. Other comparisons of $\mathrm{P} 4$ values to fertility analyses were not our primary hypotheses and were not subjected to power calculations. The distribution of cows by presynchronization treatment into the low, medium, 
and high P4 classes at GnRH1 of Ovsynch-56 and d 11 after TAI were compared using Fisher's exact test. The relationship between the predicted probability of pregnancy and concentrations of $\mathrm{P} 4$ on $\mathrm{d} 11$ after TAI was determined using logistic regression with the LOGISTIC procedure. The OUTPUT statement was used to obtain values for the predicted probability. The model used contained the effect of treatment and the linear effect of $\mathrm{P} 4$ concentration on d 11, modeled as a continuous effect, as well as their interaction. Animals with $<2.00 \mathrm{ng} / \mathrm{mL} \mathrm{P} 4$ on d 11 after TAI $(\mathrm{n}=95)$ were removed from this analysis, and animals with $\geq 8.00$ $\mathrm{ng} / \mathrm{mL} \mathrm{P} 4(\mathrm{n}=13)$ were coded as $\mathrm{P} 4=7.99 \mathrm{ng} / \mathrm{mL}$.

\section{RESULTS}

\section{Treatment, Parity, and BCS Effects on Fertility at First Postpartum Service}

Presynchronization with DO increased P/AI (1.21fold) compared with PS (46.3 vs. $38.2 \%, P=0.01$, DO vs. PS, respectively). Parity (Table 1$)$ affected $(P<$ 0.001) $\mathrm{P} / \mathrm{AI}$ at first postpartum service, with primiparous cows having greater $\mathrm{P} / \mathrm{AI}(47.3 \%)$ than multiparous cows $(37.3 \%)$. Primiparous cows treated with DO had greater (1.24-fold) $\mathrm{P} / \mathrm{AI}$ than did those treated with PS (52.5 vs. $42.3 \%, P=0.02$, DO primiparous vs. PS primiparous). Multiparous cows tended to have greater (1.17-fold) P/AI with DO than with PS (40.3 vs. $34.3 \%, P=0.07$, DO multiparous vs. PS multiparous; Table 1 ).

Greater BCS improved P/AI (46.6 vs. $37.9 \%, P=$ 0.004 , high BCS vs. low BCS), with BCS tending to have an effect in PS cows (43.5 vs. $33.3 \%, P=0.08$, PS high BCS vs. PS low BCS), but not in DO cows (49.8 vs. $42.9 \%, P=0.3$, DO high BCS vs. DO low BCS). The $\mathrm{P} / \mathrm{AI}$ was greater for $\mathrm{DO}$ than for $\mathrm{PS}$ in both high- and low-BCS cows (49.8 vs. $43.5 \%, P=0.05, \mathrm{DO}$ high vs. PS high and 42.9 vs. $33.3 \%, P=0.04$, DO low vs. PS low).

Late embryonic loss (d 39 to 74 after AI) was not altered by method of presynchronization ( 8.5 vs. $5.5 \%$, $P=0.3$, DO vs. PS) or BCS (6.0 vs. $7.9 \%, P=0.6$, high vs. low). However, late embryo loss was less for primiparous than multiparous cows (3.5 vs. $13.0 \%, P$ $=0.006)$.

\section{Circulating P4 at GnRH1 of Ovsynch-56}

Mean P4 concentrations at GnRH1 of Ovsynch-56 were not affected by presynchronization treatment (2.65 vs. $2.49 \mathrm{ng} / \mathrm{mL}, P=0.2, \mathrm{DO}$ vs. PS) or parity (2.90 vs. $2.24 \mathrm{ng} / \mathrm{mL}, P=0.17$; primiparous vs. multiparous). Greater BCS increased P4 concentrations at GnRH1 of Ovsynch-56 (2.87 vs. $2.27 \mathrm{ng} / \mathrm{mL}, P<0.001$, high vs. low). A tendency for greater P4 concentrations at GnRH1 was observed for multiparous cows treated with DO than those treated with PS $(2.40$ vs. $2.07 \mathrm{ng} / \mathrm{mL}, P$ $=0.07$, DO multiparous vs. PS multiparous), with no increase observed for primiparous animals (2.91 vs. 2.90 $\mathrm{ng} / \mathrm{mL}, P=0.9$; DO primiparous vs. PS primiparous). A significant treatment $\times$ BCS interaction $(P=0.04)$ was observed for P4 concentrations at GnRH1. LowBCS animals had greater P4 concentrations at GnRH1 when treated with DO than with PS (2.50 vs. $2.04 \mathrm{ng} /$ $\mathrm{mL}, P=0.04$, DO low vs. PS low), with no difference observed for high-BCS cows (2.81 vs. $2.93 \mathrm{ng} / \mathrm{mL}, P$ $=0.5$, DO high vs. PS high). Milk production within lactation number had no effect $(P=0.8)$ on $\mathrm{P} 4$ at GnRH1.

Table 1. Effect of parity on pregnancies per AI in lactating dairy cows following presynchronization with Double-Ovsynch or Presynch-Ovsynch ${ }^{1}$

\begin{tabular}{|c|c|c|c|c|c|}
\hline \multirow[b]{2}{*}{ Item } & \multicolumn{2}{|c|}{ Primiparous } & \multicolumn{2}{|c|}{ Multiparous } & \multirow[b]{2}{*}{$P$-value* } \\
\hline & Unadjusted & Adjusted & Unadjusted & Adjusted & \\
\hline Double-Ovsynch (\%) & $\begin{array}{l}52.9 \\
(207\end{array}$ & 1) 52.5 & $\begin{array}{l}39.5 \\
(176\end{array}$ & 6) & 0.006 \\
\hline Presynch-Ovsynch (\%) & ${ }^{47.5}(184$ & 7) 42.3 & $\begin{array}{l}35.6 \\
(165\end{array}$ & 3) 34.3 & 0.13 \\
\hline $\begin{array}{l}P \text {-value } \ddagger \\
\text { Overall }(\%)\end{array}$ & $50.2 \quad 0$ & 8) 47.3 & $\begin{array}{r}37.5 \quad 0 \\
\quad(341\end{array}$ & 9) 37.3 & $<\overline{0.001}$ \\
\hline
\end{tabular}

\footnotetext{
${ }^{1}$ Animals assigned to Presynch-Ovsynch received 2 injections of $\mathrm{PGF}_{2 \alpha}$ at $45 \pm 3 \mathrm{DIM}$ and $59 \pm 3 \mathrm{DIM}$ and then began the Ovsynch-56 timed AI (TAI) protocol 12 d later. Animals assigned to Double-Ovsynch received $\mathrm{GnRH}$ at $54 \pm 3 \mathrm{DIM}$, followed by an injection of $\mathrm{PGF}_{2 \alpha} 7 \mathrm{~d}$ later, $\mathrm{GnRH} 72 \mathrm{~h}$ after $\mathrm{PGF}_{2 \alpha}$, and then began the Ovsynch-56 TAI protocol 7 d later. All cows received the Ovsynch-56 TAI protocol: GnRH at $71 \pm 3$ DIM, $\mathrm{PGF}_{2 \alpha} 7 \mathrm{~d}$ later, GnRH $56 \mathrm{~h}$ after $\mathrm{PGF}_{2 \alpha}$, and TAI 12 to $14 \mathrm{~h}$ later at $81 \pm 3$ DIM.

* $P$-values for comparison of primiparous versus multiparous.

$\ddagger P$-values for comparison of Double-Ovsynch versus Presynch-Ovsynch.
} 


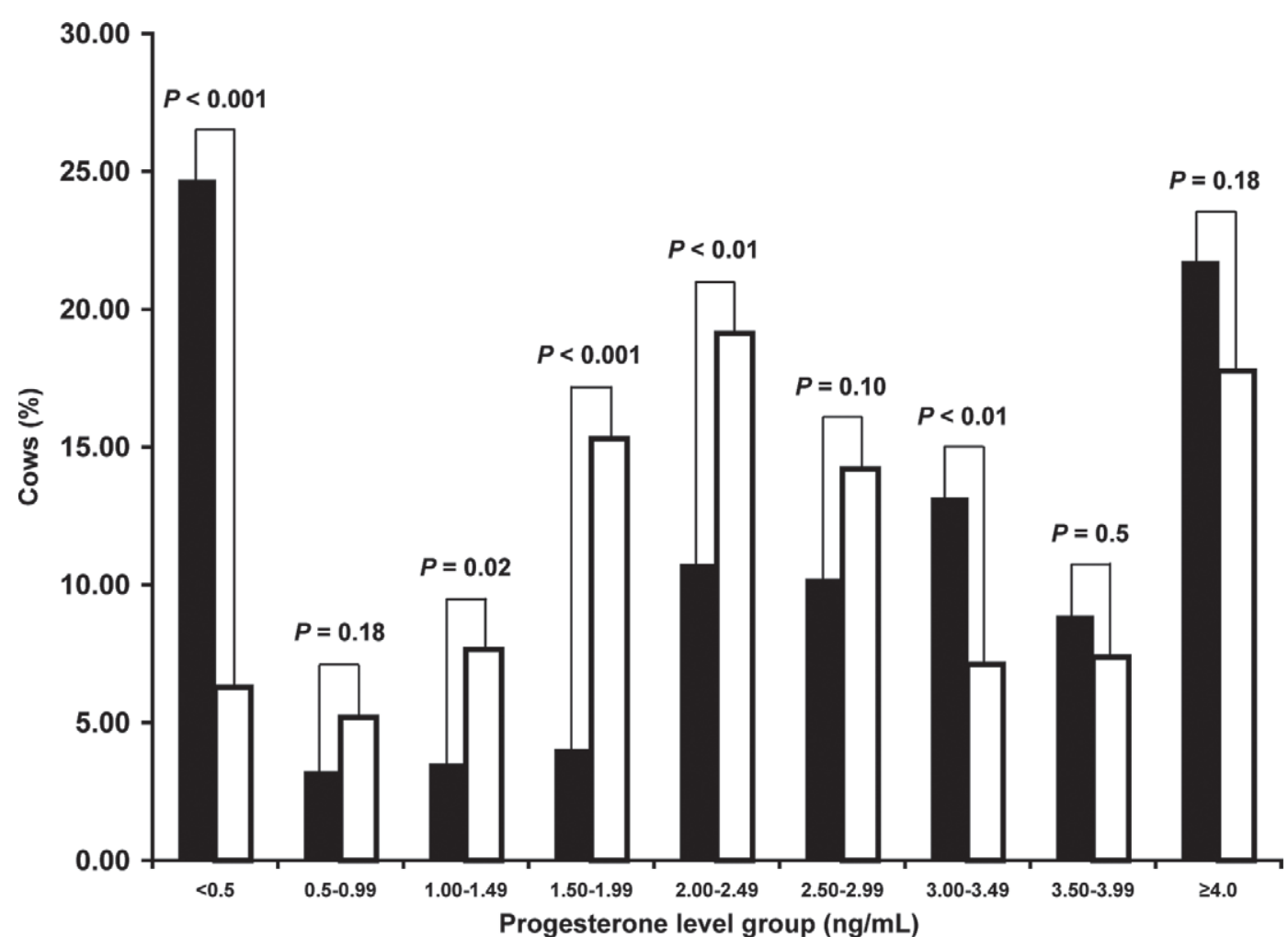

Figure 2. Distribution of cows according to circulating progesterone concentrations at the first GnRH of the Ovsynch-56 timed AI protocol for Double-Ovsynch (open bars) and Presynch-Ovsynch (solid bars).

The distribution of cows by circulating P4 concentrations at GnRH1 of Ovsynch-56 for the 2 treatment groups is illustrated in Figure 2. Presynchronization with DO reduced the percentage of animals with low P4 concentrations at GnRH1 of Ovsynch-56 (6.3 vs. $24.7 \%, P<0.001$, DO vs. PS). In addition, presynchronization with DO increased (all $P<0.05$ ) the percentage of cows in the following $\mathrm{P} 4$ level groups (1.00 to $1.49 \mathrm{ng} / \mathrm{mL}, 1.50$ to $1.99 \mathrm{ng} / \mathrm{mL}$, and 2.00 to $2.49 \mathrm{ng} /$ $\mathrm{mL}$ ) at the onset of Ovsynch-56 (42.1 vs. $18.2 \%$, DO vs. PS).

A greater percentage of multiparous than primiparous cows had low $\mathrm{P} 4$ concentrations at GnRH1 (8.3 vs. $17.5 \%, P=0.004$; primiparous vs. multiparous). Mean BCS differed $(P<0.001)$ by parity $(2.89$ vs. 2.75 , primiparous vs. multiparous). Further, a lesser percentage of both primiparous and multiparous cows had low P4 concentrations at GnRH1 when treated with DO than with PS (3.3 vs. $19.7 \%, P<0.001$; DO primiparous vs. PS primiparous; 8.8 vs. $31.9 \%, P<0.001$; DO multiparous vs. PS multiparous).

A greater BCS reduced the percentage of cows with low $\mathrm{P} 4$ concentrations at GnRH1 (8.2 vs. $17.9 \%, P<$ 0.001, high vs. low). Both high- and low-BCS cows had a lesser percentage of cows with low P4 at GnRH1 when treated with DO than with PS (3.6 vs. $17.5 \%, P$ $<0.001$, DO high vs. PS high and 8.0 vs. $35.2 \%, P<$ 0.001 , DO low vs. PS low, respectively).

An effect of presynchronization treatment $(P<$ $0.001)$ was observed on the distribution of cows in the low $(<0.50 \mathrm{ng} / \mathrm{mL})$, medium $(\geq 0.50$ to $\leq 3.00 \mathrm{ng} / \mathrm{mL})$, and high $(>3.00 \mathrm{ng} / \mathrm{mL})$ P4 categories at GnRH1 (6.3 vs. $24.7 \%$, DO low vs. PS low; 61.5 vs. $32.2 \%$, DO medium vs. PS medium; 32.2 vs. $43.2 \%$, DO high vs. PS high, respectively). Greater $\mathrm{P} 4$ concentrations at GnRH1 increased $(P=0.03) \mathrm{P} / \mathrm{AI}(32.0,45.9$, and $46.2 \%$, low, medium, and high, respectively; Table 2), with no treatment effects on $\mathrm{P} / \mathrm{AI}$ for cows with low and medium $\mathrm{P} 4$ at GnRH1 but a tendency toward a difference for cows with high P4 at GnRH1 (Table 2).

\section{Distribution and Fertility of Cows with Low, Medium, and High P4 on d 11 After TAI}

Initial analyses were performed using $0.50 \mathrm{ng} / \mathrm{mL}$ as the cutoff for low P4 concentrations. However, it became clear that few cows were in this category on $\mathrm{d}$ 11 after Ovsynch-56 $(\mathrm{n}=46)$, and almost no cows with circulating $\mathrm{P} 4$ below $2.00 \mathrm{ng} / \mathrm{mL}$ on d 11 after TAI were found to be pregnant $(5.8 \%)$. Therefore, a value 
Table 2. Pregnancies per AI for cows with low, medium, and high progesterone (P4) concentrations at the first GnRH of the Ovsynch-56 timed AI protocol following presynchronization with Double-Ovsynch or Presynch-Ovsynch ${ }^{1,2}$

\begin{tabular}{lccc}
\hline Item & Low P4 & Medium P4 & High P4 \\
\hline Double-Ovsynch (\%) & $25.0^{\mathrm{a}}$ & $45.5^{\mathrm{ab}}$ & $51.7^{\mathrm{b}}$ \\
& $(6 / 23)$ & $(102 / 225)$ & $(61 / 118)$ \\
Presynch-Ovsynch (\%) & $33.3^{\mathrm{a}}$ & $46.6^{\mathrm{b}}$ & $42.1^{\mathrm{ab}}$ \\
& $(31 / 92)$ & $(56 / 120)$ & $(68 / 161)$ \\
P-value $\ddagger$ & 0.3 & 0.4 & 0.06 \\
Overall (\%) & $32.0^{\mathrm{a}}$ & $45.9^{\mathrm{b}}$ & $46.2^{\mathrm{b}}$ \\
& $(37 / 115)$ & $(158 / 345)$ & $(129 / 279)$ \\
\hline
\end{tabular}

${ }^{\mathrm{a}, \mathrm{b}}$ Means within a row with different superscripts differ $(P<0.05)$.

${ }^{1}$ Unadjusted and adjusted means were identical.

${ }^{2}$ Low P4: $<0.50 \mathrm{ng} / \mathrm{mL}$; medium P4: $\geq 0.50$ to $\leq 3.00 \mathrm{ng} / \mathrm{mL}$; high $\mathrm{P} 4$ : $>3.00 \mathrm{ng} / \mathrm{mL}$.

$\ddagger P$-values for comparison of Double-Ovsynch versus PresynchOvsynch.

* $P$-value for comparison of low versus medium versus high $\mathrm{P} 4(P=$ $0.06)$.

of $2.00 \mathrm{ng} / \mathrm{mL}$ at d 11 was used as the cutoff for low circulating P4. Other cutoff values (3.50 and $5.00 \mathrm{ng} /$ $\mathrm{mL}$ ) were chosen to provide relatively high numbers of cows in each $\mathrm{P} 4$ group. The logistic regression of $\mathrm{P} 4$ $(>2.00 \mathrm{ng} / \mathrm{mL})$ on $\mathrm{d} 11$ found effects of treatment $(P=$ $0.09), \mathrm{P} 4(P=0.04)$, and a treatment $\times \mathrm{P} 4$ interaction $(P=0.04)$ such that $\mathrm{P} / \mathrm{AI}$ increased as $\mathrm{P} 4$ increased in cows treated with DO (linear increase from $39 \%$ at $2.00 \mathrm{ng} / \mathrm{mL}$ to $70 \%$ at $8.00 \mathrm{ng} / \mathrm{mL}$ ) but $\mathrm{P} / \mathrm{AI}$ did not change with increasing $\mathrm{P} 4$ in cows treated with PS (no significant linear trend with $48 \%$ for all P4 concentrations above $2.00 \mathrm{ng} / \mathrm{mL}$ ).

Presynchronization with DO decreased $\mathrm{P} 4$ concentrations on d 11 after TAI $(3.72$ vs. $4.01 \mathrm{ng} / \mathrm{mL}, P=$ 0.03, DO vs. PS). Milk production reduced $(P=0.004)$ $\mathrm{P} 4$ concentrations on d 11 after TAI. Primiparous animals had greater P4 concentrations on d 11 after TAI compared with multiparous animals (4.41 vs. $3.31 \mathrm{ng} /$ $\mathrm{mL}, P<0.001$, primiparous vs. multiparous). Further, multiparous cows treated with DO had lower P4 on d 11 after TAI compared with multiparous cows treated with PS (3.13 vs. $3.49 \mathrm{ng} / \mathrm{mL}, P=0.04$, DO multiparous vs. PS multiparous), with no decrease observed for primiparous animals $(4.31$ vs. $4.50 \mathrm{ng} / \mathrm{mL}, P=0.3$, DO primiparous vs. PS primiparous).

Greater BCS increased P4 concentrations on d 11 after TAI (4.09 vs. $3.64 \mathrm{ng} / \mathrm{mL}, P<0.001$, high vs. low). A tendency toward a significant treatment $\times$ BCS interaction $(P=0.09)$ was observed for $\mathrm{P} 4$ concentrations on d 11 after TAI. High-BCS cows treated with DO had lesser P4 concentrations on d 11 after TAI compared with high-BCS cows treated with PS (3.84 vs. $4.34 \mathrm{ng} / \mathrm{mL}, P=0.002$, DO high vs. PS high), with no decrease observed for low-BCS animals (3.61 vs. $3.67 \mathrm{ng} / \mathrm{mL}, P=0.8$, DO low vs. PS low, respectively).

Cows with low $\mathrm{P} 4$ at GnRH1 had lesser $(P<0.001)$ P4 concentrations on d 11 after TAI compared with cows with high $\mathrm{P} 4$ at GnRH1 (3.38 vs. $4.35 \mathrm{ng} / \mathrm{mL}$ ). Cows with double ovulations $(\mathrm{n}=96)$ had greater $(P$ $<0.001$ ) P4 concentrations on d 11 after TAI compared with cows with single ovulations (4.54 vs. $3.19 \mathrm{ng} / \mathrm{mL}$ ).

A significant difference $(P=0.02)$ was observed in the distribution of cows by presynchronization treatment in the low $(<2.00 \mathrm{ng} / \mathrm{mL})$, medium1 $(\geq 2.00$ to $<3.50 \mathrm{ng} / \mathrm{mL})$, medium2 $(\geq 3.50$ to $\leq 5.00 \mathrm{ng} / \mathrm{mL})$, and high $(>5.00 \mathrm{ng} / \mathrm{mL})$ P4 categories on d 11 after TAI (11.4 vs. $14.7 \%$, DO low vs. PS low; 36.3 vs. $27.0 \%$, DO medium1 vs. PS medium1; 33.2 vs. $33.0 \%$, DO medium2 vs. PS medium2; 19.1 vs. $25.3 \%$, DO high vs. PS high). Greater P4 concentrations on d 11 after TAI improved $(P<0.001) \mathrm{P} /$ AI at first postpartum service $(5.8,46.0,50.0$, and $52.2 \%$ for low, medium1, medium 2 , and high, respectively; Table 3). This increase in $\mathrm{P} /$ AI with increasing $\mathrm{P} 4$ on $\mathrm{d} 11$ was observed in cows treated with either DO $(P<0.001)$ or PS $(P=0.04)$. Because the lowest $\mathrm{P} 4$ category produced such low $\mathrm{P} /$ AI results, we suspected that this category was dominating the P4-P/AI relationship. Therefore, we carried out an analysis of $\mathrm{P} 4$ concentration as a continuous variable compared with the predicted probability of pregnancy without the lowest P4 category. A tendency was observed for a presynchronization treatment effect $(P=0.09)$, with a significant effect of $\mathrm{P} 4(P=0.03)$ and a presynchronization treatment $\times \mathrm{P} 4$ interaction $(P=0.04)$. The interaction was due to increasing $\mathrm{P} / \mathrm{AI}$ with increasing $\mathrm{P} 4$ in cows treated with $\mathrm{DO}$ but not in cows treated with PS (Figure 3 ).

Mean luteal volume differed $(P<0.001)$ for cows with differing $\mathrm{P} 4$ on $\mathrm{d} 11(7,116,14,482,16,504$, and $17,003 \mathrm{~mm}^{3}$ for low, medium1, medium2, and high, respectively). No effect was observed for presynchronization treatment $\left(15,928\right.$ vs. $15,958 \mathrm{~mm}^{3}, P=0.9, \mathrm{DO}$ vs. PS) or BCS $\left(16,145\right.$ vs. $15,741 \mathrm{~mm}^{3}, P=0.6$, high vs. low) on CL volume on d 11 after TAI. Parity had a significant effect on CL volume on d 11 (16,607 vs. $15,278 \mathrm{~mm}^{3}, P=0.03$, primiparous vs. multiparous). The percentage of cows with a CL present on $\mathrm{d} 11$ was high and was not altered by the presynchronization treatment (97.2 vs. $97.5, P=0.7$, DO vs. PS) or BCS (97.3 vs. $97.5, P=0.8$, high vs. low). However, a greater percentage of primiparous than multiparous cows had a CL present on d 11 (98.7 vs. 94.7, $P=$ 0.003, primiparous vs. multiparous, respectively) and a greater $(P<0.001)$ percentage of cows with low versus high $\mathrm{P} 4$ at GnRH1 did not have a CL present on $\mathrm{d}$ 
Table 3. Pregnancies per AI for cows with low, medium, and high progesterone (P4) concentrations on d 11 after timed AI following presynchronization with Double-Ovsynch or Presynch-Ovsynch ${ }^{1,2}$

\begin{tabular}{lcccc}
\hline Item & Low P4 & Medium1 P4 & Medium2 P4 & High P4 \\
\hline Double-Ovsynch (\%) & $8.6^{\mathrm{a}}$ & $43.4^{\mathrm{b}}$ & $52.5^{\mathrm{bc}}$ & $59.4^{\mathrm{c}}$ \\
& $(4 / 41)$ & $(57 / 131)$ & $(63 / 120)$ & $(41 / 69)$ \\
Presynch-Ovsynch (\%) & $3.9^{\mathrm{a}}$ & $49.5^{\mathrm{b}}$ & $47.5^{\mathrm{b}}$ & $46.7^{\mathrm{b}}$ \\
& $(2 / 54)$ & $(49 / 99)$ & $(57 / 121)$ & $(43 / 93)$ \\
$P$-value $\ddagger$ & 0.2 & 0.2 & 0.2 & 0.06 \\
Overall (\%) & $5.8^{\mathrm{a}}$ & $46.0^{\mathrm{b}}$ & $50.0^{\mathrm{b}}$ & $52.2^{\mathrm{b}}$ \\
& $(6 / 95)$ & $(106 / 230)$ & $(121 / 241)$ & $(85 / 162)$ \\
\hline
\end{tabular}

${ }^{\mathrm{a}-\mathrm{c}}$ Means within a row with different superscripts differ $(P<0.05)$.

${ }^{1}$ Unadjusted and adjusted means were identical.

${ }^{2}$ Low P4: $<2.00 \mathrm{ng} / \mathrm{mL}$; medium1 P4: $\geq 2.00$ to $<3.50 \mathrm{ng} / \mathrm{mL}$; medium2 P4: $\geq 3.50$ to $\leq 5.00 \mathrm{ng} / \mathrm{mL}$;igh P4: $>5.00 \mathrm{ng} / \mathrm{mL}$.

$\ddagger P$-values for comparison of Double-Ovsynch versus Presynch-Ovsynch.

$* P$-value for comparison of low versus medium1 versus medium2 versus high $\mathrm{P} 4(P<0.001)$.

11 (86.5 vs. 98.1\%). Further, cows with double ovulations had greater $(P<0.001)$ CL volume on $\mathrm{d} 11$ than cows with single ovulations $\left(17,617\right.$ vs. $\left.14,268 \mathrm{~mm}^{3}\right)$, although presynchronization treatment (13.7 vs. $16.4 \%$, $P=0.4$, DO vs. PS) or BCS (17.5 vs. $12.8 \%, P=0.13$, high vs. low) had no effect on the incidence of double ovulation. As expected, primiparous cows had fewer double ovulations than did multiparous cows (11.4 vs. $19.4 \%, P=0.02$; primiparous vs. multiparous).

\section{P/Al at Second Postpartum Service}

The $\mathrm{P} / \mathrm{AI}$ at second postpartum AI were not affected by presynchronization treatment at first service $(34.7$ vs. $36.5 \%, P=0.7$, DO vs. PS), parity (39.9 vs. $31.5 \%$, $P=0.14$, primiparous vs. multiparous), or BCS (34.1 vs. $37.2 \%, P=0.6$, high vs. low). The interaction between presynchronization treatment and parity on $\mathrm{P} /$ $\mathrm{AI}$ at second service was not significant $(P=0.9)$, and

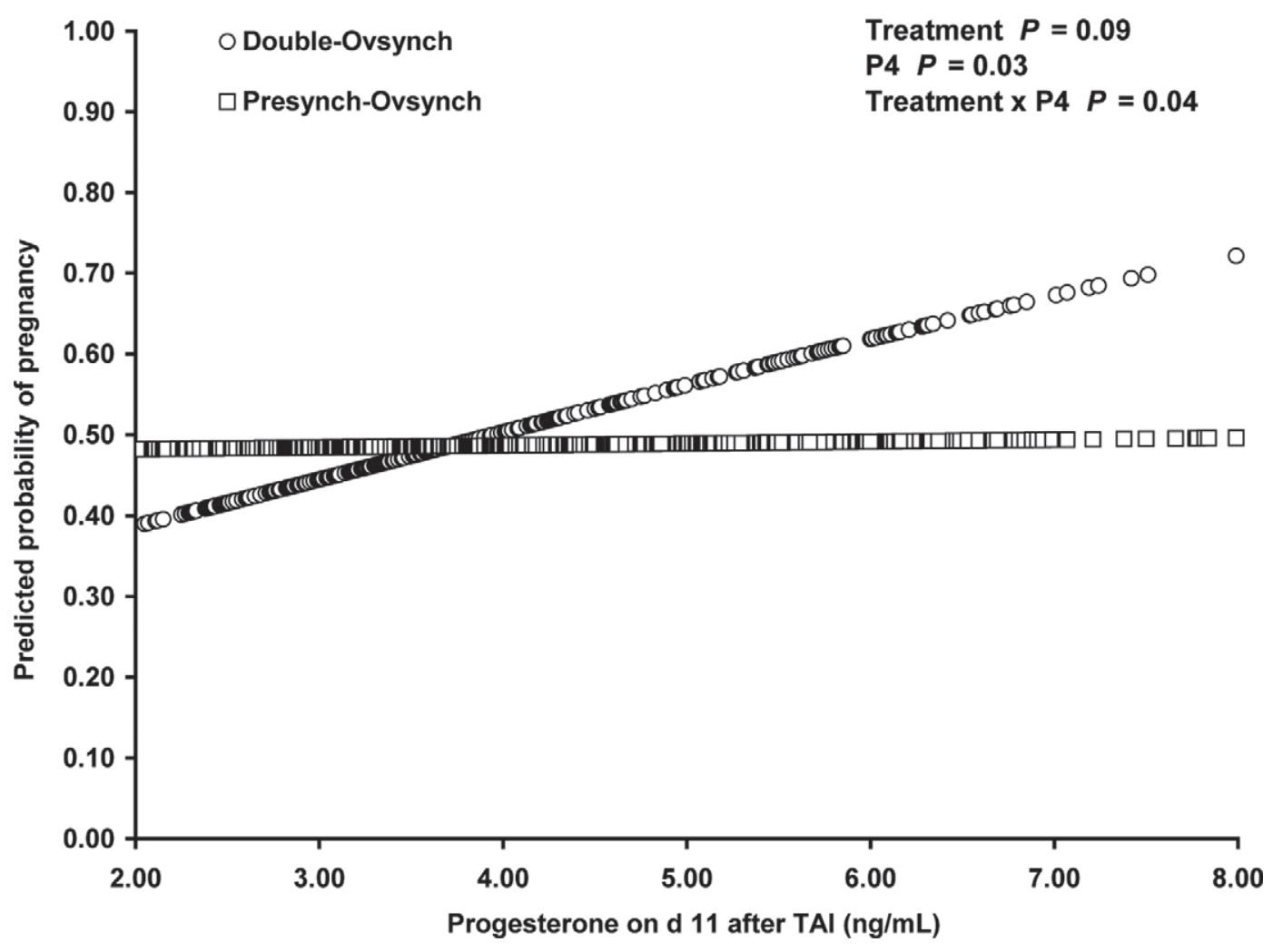

Figure 3. Logistic regression of progesterone (P4) concentration $(\geq 2.00 \mathrm{ng} / \mathrm{mL}$ ) on d 11 after timed AI (TAI) versus P/AI in cows treated with either Double-Ovsynch or Presynch-Ovsynch. 
preplanned contrasts used to compare treatment effects within parity revealed no differences in $\mathrm{P} / \mathrm{AI}$ at second AI (38.3 vs. $41.5 \%, P=0.8, \mathrm{DO}$ primiparous vs. PS primiparous, and 31.0 vs. $32.0 \%, P=0.9$, DO multiparous vs. PS multiparous, respectively). In addition, no interaction was observed between presynchronization treatment and $\mathrm{BCS}$ on $\mathrm{P} / \mathrm{AI}$ at second service $(P=$ $0.9)$.

\section{DISCUSSION}

The primary hypothesis for this research was that improved P/AI following Ovsynch-56 can be achieved at the first service of first-parity cows through the use of Ovsynch for presynchronization (i.e., DO) compared with PS. The PS program had previously been shown to increase fertility compared with Ovsynch alone (Navanukraw et al., 2004; Galvão et al., 2007). In contrast, Ovsynch alone did not improve fertility compared with AI after estrus (Pursley et al., 1997; Rabiee et al., 2005). In the present study, P/AI was further increased 1.21 -fold $(+8.1 \%$; $P=0.01)$ for cows presynchronized with DO compared with PS. All aspects of the breeding Ovsynch program and TAI were identical for the 2 groups. Primiparous cows treated with DO had the greatest improvement in $\mathrm{P} / \mathrm{AI}$, with a 1.24-fold increase. Although the increase in $\mathrm{P} / \mathrm{AI}$ with $\mathrm{DO}$ in multiparous cows was not significant $(P=0.07)$, the trend was similar and the fold increase (1.17-fold) was not greatly diminished for multiparous cows. Primiparous cows treated with $\mathrm{DO}$ had a $12.2 \%$ greater $\mathrm{P} / \mathrm{AI}$ than did multiparous cows treated with DO, whereas primiparous cows treated with PS exhibited a numerically $(8 \%)$, but not significantly, $(P=0.13)$ greater $\mathrm{P} /$ AI than did multiparous cows treated with PS. These observations support the findings of Souza et al. (2008), who reported increased $\mathrm{P} / \mathrm{AI}$ for DO compared with PS (49.7 vs. $41.7 \%$ ), with substantial improvements observed in primiparous cows (62.5 vs. $45.2 \%$, DO primiparous vs. PS primiparous) but no improvements for multiparous cows (37.5 vs. $39.3 \%$, DO multiparous vs. PS multiparous). The number of cows in the present experiment $(>1,600)$ on 3 different commercial farms provides further evidence that the DO protocol can improve fertility at first postpartum service, particularly in primiparous cows. On one of the farms, a limited number of physiological measurements were acquired on almost all cows that received the protocol in an attempt to understand the underlying reasons for any improvements in fertility. The $\mathrm{P} 4$ measurement at GnRH1 of Ovsynch-56 provided support for our hypothesis that DO improved fertility by inducing cyclicity in anovular cows. In addition, the $\mathrm{P} 4$ measurement at $\mathrm{GnRH} 1$ and $11 \mathrm{~d}$ after TAI provided evidence for new hypotheses that can be tested in future experiments, as discussed below.

It is interesting that no difference was observed in mean P4 concentrations between PS and DO at GnRH,1 and only when the distribution of $\mathrm{P} 4$ values was evaluated could the major effects of DO be identified. Clearly, treatment with an Ovsynch protocol before beginning Ovsynch-56 (i.e., DO protocol) dramatically reduced the percentage of cows with low $\mathrm{P} 4$ at GnRH1 compared with the PS protocol, with almost a 5 -fold difference ( 25.3 vs. $5.4 \%$ ) between these groups in the incidence of anovulation at GnRH1. The finding that approximately $25 \%$ of lactating dairy cows were anovular was consistent with numerous other studies (Moreira et al., 2001; Gümen et al., 2003; Walsh et al., 2007) and with a recent study examining the prevalence of anovulation from 13 previous large studies in commercial dairy herds in the United States (Bamber et al., 2009). However, this was at the upper range of what was observed in a series of studies reviewed by Crowe (2008). Moreira et al. (2001) previously reported improved P/AI for cyclic animals with the PS strategy, probably because of most cows being on $\mathrm{d} 5$ to 11 of the estrous cycle at the initiation of Ovsynch (Vasconcelos et al., 1999). It seems clear that DO not only reduced the percentage of cows with low $\mathrm{P} 4$ but also increased the percentage of cows with intermediate P4 (1.00 to $3.00 \mathrm{ng} / \mathrm{mL}$ ). The reason for the lack of difference in mean P4 concentrations was that PS had proportionally more cows with very low or greater P4 (>3.00 ng/ $\mathrm{mL}$ ), whereas DO had more cows with intermediate concentrations of $\mathrm{P} 4$. One puzzling aspect of the data was that a greater proportion of multiparous cows were anovular at GnRH1 of Ovsynch-56 compared with primiparous cows. This contrasts with previous studies that generally have reported a greater prevalence of anovulation in primiparous cows compared with multiparous cows (Moreira et al., 2001; Gümen et al., 2003; Silva et al., 2007). For example, the multistudy analysis reported by Bamber et al. (2009) indicated 29.6\% anovulation in primiparous cows and $19.1 \%$ anovulation in multiparous cows. The reason for the high incidence of anovulation in multiparous cows in our study was not clear. Nevertheless, the dramatic decrease in anovulation induced by DO $(P<0.001)$ in either primiparous or multiparous cow indicates that DO was effective at inducing cyclicity regardless of parity and was unlikely to provide an adequate explanation for any parity differences observed with DO. Other studies have also observed reduced fertility in multiparous cows compared with primiparous cows using various protocols (Moreira et al., 2001; Gümen et al., 2003; Silva et al., 2007), and these differences have not yet been adequately explained. It is interesting that in the pres- 
ent study, mean BCS on d 11 after TAI was greater for primiparous cows than multiparous cows (2.88 vs. 2.75 , primiparous vs. multiparous, respectively). This may partially explain the greater incidence of anovulation at GnRH1 in multiparous cows. Body condition score can be used as an indirect measure of energy balance and is an indicator of the nutritional status of an animal (Butler, 2000, 2003; Roche et al., 2009). Other studies have shown effects similar to those we observed, with lower BCS reducing fertility to TAI protocols (Moreira et al., 2000; Santos et al., 2009; Galvão and Santos, 2010).

Although not evaluated in the present study, another potential underlying reason for the improved fertility observed with DO could be the greater proportion of cows with elevated $\mathrm{P} 4$ concentrations at the time of $\mathrm{PGF}_{2 \alpha}$ treatment during DO, as reported previously (Souza et al., 2008; Wiltbank et al., 2011a). Greater P4 concentrations during growth of the dominant follicle in a DO protocol resulted in smaller ovulatory follicle size (Brusveen et al., 2009; Wiltbank et al., 2011a) and a greater percentage of grade 1 embryos recovered on $\mathrm{d}$ 7 to 8 after AI (Wiltbank et al., 2011a). Consequently, the improved fertility observed for animals treated with DO may be related to a more favorable hormonal milieu, in particular, improvements in circulating $\mathrm{P} 4$, during growth and development of the ovulatory follicle. For animals treated with DO, greater circulating concentrations of $\mathrm{P} 4$ during early growth of the ovulatory follicle may have decreased LH pulsatility, possibly improving competency of the dominant follicle, the quality of the ovulated oocyte, or both (Mihm et al., 1994; Revah and Butler, 1996) and the quality of the resultant embryo (Wiltbank et al., 2011a). Other recent studies have also suggested that greater circulating concentrations of $\mathrm{P} 4$ at the time of $\mathrm{PGF}_{2 \alpha}$ can improve fertility (Bello et al., 2006; Martins et al., 2011). Although not evaluated in the present study, it is possible that differences in luteolytic responses to $\mathrm{PGF}_{2 \alpha}$ may partially account for the improvements in fertility outcomes observed for primiparous cows treated with DO when compared with multiparous cows. Martins et al. (2011) recently reported greater rates of luteolysis for primiparous cows compared with multiparous cows treated with Ovsynch-56. Previous studies have shown that incomplete luteal regression resulting in elevated $\mathrm{P} 4$ concentrations of $>0.50 \mathrm{ng} / \mathrm{mL}$ (Souza et al., 2007) or $>0.40 \mathrm{ng} / \mathrm{mL}$ (Brusveen et al., 2009) near TAI reduced P/AI by more than $50 \%$ in animals treated with Ovsynch. Thus, inadequate circulating P4 in multiparous cows, coupled with potentially lower rates of luteal regression in multiparous cows may partially explain the reduced effectiveness of DO in multiparous cows.
In the present study, we also evaluated circulating P4 concentrations and luteal size at d 11 after TAI, a time that has not been adequately studied in previous trials. Our hypothesis was that use of DO would reduce the incidence of short cycles, because of induction of cyclicity, and thereby improve fertility. Consistent with this idea, cows with low P4 at GnRH1 of Ovsynch-56 had an increased incidence of low P4 at d 11 after TAI. Nevertheless, no treatment differences in the incidence of low $\mathrm{P} 4$ at $\mathrm{d} 11$ after TAI were observed when using either $<0.50$ or $<2.00 \mathrm{ng} / \mathrm{mL}$ as the threshold value for low P4. It was clearly observed that cows with low P4 at d 11 after TAI had substantially reduced fertility to the TAI, regardless of presynchronization treatment. This was logical because low P4 on d $11(<2.00 \mathrm{ng} /$ $\mathrm{mL}$ ) would indicate either a lack of synchronization to the protocol or an early luteal regression. Only $13 \%$ of cows fell into this group, with no differences between DO and PS. Overall, cows on DO had lower mean P4 concentrations on d 11 after TAI than did cows on PS. It seems logical that the lower circulating $\mathrm{P} 4$ would have resulted from ovulation of a smaller follicle after DO, although we did not make this measurement in the present study. Contrary to this idea, the luteal volume on d 11 was not altered by presynchronization method. A particularly interesting observation that will need to be confirmed in future studies is that cows treated with DO had increased fertility with increasing P4 (cows with $\mathrm{P} 4 \geq 2.00 \mathrm{ng} / \mathrm{mL}$ only). This trend was not seen for PS cows. This seems to indicate that cows presynchronized with DO are primarily limited by inadequate P4 after ovulation, perhaps because of the size or granulosa cell content of the ovulatory follicle. Other factors may be more limiting in cows presynchronized with PS. Clearly, DO altered the distribution of cows by $\mathrm{P} 4$ concentrations on $\mathrm{d} 11$, and this may offer a clue to improving this protocol. Obviously, this hypothesis should be viewed as speculative at this time because it was discovered only by post hoc analysis of our fertility data, and adequate testing will require future experimentation.

Other interesting observations that were not part of our primary hypotheses related to double ovulation and P/AI at second service. Increases in double ovulation have been observed with increasing milk production (Fricke and Wiltbank, 1999; Lopez et al., 2005a), increasing parities (Fricke and Wiltbank, 1999), and reduced P4 during follicle growth (Lopez et al., 2005b). Although no treatment differences in double ovulation rate were detected in the present study, a lesser incidence of double ovulation on d 11 after TAI was observed for primiparous animals compared with multiparous animals, in agreement with the findings of 
Fricke and Wiltbank (1999). The findings of the present study also suggest that cows with low P4 concentrations at GnRH1 of Ovsynch-56 had a greater incidence of double ovulation on d 11 after TAI. Lopez et al. (2005b) suggested that selection of multiple dominant follicles in lactating dairy cows appears to be related to transient increases in circulating FSH during the $24 \mathrm{~h}$ before deviation, possibly because of increased GnRH, as a result of lesser circulating $\mathrm{P} 4$ concentrations. Finally, we planned in advance to evaluate the fertility at second AI because of the presynchronization protocol at first service, owing to speculation in the industry that the high fertility of DO at first AI may reduce the fertility at second AI. We observed no effect of DO compared with PS for first AI on P/AI at the subsequent second service.

\section{CONCLUSIONS}

The present study demonstrated that DO increased fertility in lactating dairy cows compared with the PS protocol. The primary effect was observed in primiparous cows, with only a tendency for improvement observed in multiparous cows. Treatment with DO dramatically reduced the proportion of cows in anovulatory anestrus at the start of the Ovsynch protocol, and this may underlie part of the improvement in fertility. The greater uniformity of intermediate $\mathrm{P} 4$ concentrations at the start of Ovsynch may also be a factor in the fertility improvement with DO. In addition, a detectable change in distribution of $\mathrm{P} 4$ was observed on $\mathrm{d} 11$ after TAI in cows treated with DO compared with PS. The physiological and practical implications of these changes in $\mathrm{P} 4$ remain to be elucidated.

\section{ACKNOWLEDGMENTS}

The authors thank the participating herd owners and their staff for their help and cooperation during the experiment. We also thank Josie Lewandowski, Department of Dairy Science, University of Wisconsin, for assistance with the P4 assays.

\section{REFERENCES}

Bamber, R. L., G. E. Shook, M. C. Wiltbank, J. E. Santos, and P. M. Fricke. 2009. Genetic parameters for anovulation and pregnancy loss in dairy cattle. J. Dairy Sci. 92:5739-5753.

Bello, N. M., J. P. Steibel, and J. R. Pursley. 2006. Optimizing ovulation to first GnRH improved outcomes to each hormonal injection of Ovsynch in lactating dairy cows. J. Dairy Sci. 89:3413-3424.

Brusveen, D. J., A. P. Cunha, C. D. Silva, P. M. Cunha, R. A. Sterry, E. P. B. Silva, J. N. Guenther, and M. C. Wiltbank. 2008. Altering the time of the second gonadotropin-releasing hormone injection and artificial insemination (AI) during Ovsynch affects pregnancies per AI in lactating dairy cows. J. Dairy Sci. 91:1044-1052.
Brusveen, D. J., A. H. Souza, and M. C. Wiltbank. 2009. Effects of additional prostaglandin $\mathrm{F}_{2 \alpha}$ and estradiol-17 $\beta$ during Ovsynch in lactating dairy cows. J. Dairy Sci. 92:1412-1422.

Butler, W. R. 2000. Nutritional interactions with reproductive performance in dairy cattle. Anim. Reprod. Sci. 60-61:449-457.

Butler, W. R. 2003. Energy balance relationships with follicular development, ovulation and fertility in postpartum dairy cows. Livest. Prod. Sci. 83:211-218.

Crowe, M. A. 2008. Resumption of ovarian cyclicity in post-partum beef and dairy cows. Reprod. Domest. Anim. 43(Suppl. 5):20-28.

Edmonson, A. J., I. J. Lean, L. D. Weaver, T. Farver, and G. Webster. 1989. A body condition scoring chart for Holstein dairy cows. J. Dairy Sci. 72:68-78.

Fricke, P. M., and M. C. Wiltbank. 1999. Effect of milk production on the incidence of double ovulation in dairy cows. Theriogenology $52: 1133-1143$

Galvão, K. N., M. F. Sá Filho, and J. E. P. Santos. 2007. Reducing the interval from presynchronization to initiation of timed artificial insemination improves fertility in dairy cows. J. Dairy Sci. 90:4212-4218.

Galvão, K. N., and J. E. Santos. 2010. Factors affecting synchronization and conception rate after the Ovsynch protocol in lactating Holstein cows. Reprod. Domest. Anim. 45:439-446.

Gümen, A., J. N. Guenther, and M. C. Wiltbank. 2003. Follicular size and response to Ovsynch versus detection of estrus in anovular and ovular lactating dairy cows. J. Dairy Sci. 86:3184-3194.

Lopez, H., D. Z. Caraviello, L. D. Satter, P. M. Fricke, and M. C. Wiltbank. 2005a. Relationship between level of milk production and multiple ovulations in lactating dairy cows. J. Dairy Sci. 88:2783-2793.

Lopez, H., R. Sartori, and M. C. Wiltbank. 2005b. Reproductive hormones and follicular growth during development of one or multiple dominant follicles in cattle. Biol. Reprod. 72:788-795.

Martins, J. P. N., R. K. Policelli, L. M. Neuder, W. Raphael, and J. R. Pursley. 2011. Effects of cloprostenol sodium at final prostaglandin $\mathrm{F}_{2 \alpha}$ of Ovsynch on complete luteolysis and pregnancy per artificial insemination in lactating dairy cows. J. Dairy Sci. 94:2815-2824.

Mihm, M., A. Baguisi, M. P. Boland, and J. F. Roche. 1994. Association between the duration of dominance of the ovulatory follicle and pregnancy rate in beef heifers. J. Reprod. Fertil. 102:123-130.

Moreira, F., C. Orlandi, C. A. Risco, R. Mattos, F. Lopes, and W. W. Thatcher. 2001. Effects of presynchronization and bovine somatotropin on pregnancy rates to a timed artificial insemination protocol in lactating dairy cows. J. Dairy Sci. 84:1646-1659.

Moreira, F., C. Risco, M. F. A. Pires, J. D. Ambrose, M. Drost, M. DeLorenzo, and W. W. Thatcher. 2000. Effect of body condition on reproductive efficiency of lactating dairy cows receiving a timed insemination. Theriogenology 53:1305-1319.

Navanukraw, C., D. A. Redmer, L. P. Reynolds, J. D. Kirsch, A. T. Grazul-Bilska, and P. M. Fricke. 2004. A modified presynchronization protocol improves fertility to timed artificial insemination in lactating dairy cows. J. Dairy Sci. 87:1551-1557.

NRC. 2001. Nutrient Requirements of Dairy Cattle. 7th rev. ed. Natl. Acad. Sci., Washington, DC.

Pursley, J. R., M. R. Kosorok, and M. C. Wiltbank. 1997. Reproductive management of lactating dairy cows using synchronization of ovulation. J. Dairy Sci. 80:301-306.

Pursley, J. R., M. O. Mee, and M. C. Wiltbank. 1995. Synchronization of ovulation in dairy cows using $\mathrm{PGF}_{2 \alpha}$ and $\mathrm{GnRH}$. Theriogenology 44:915-923.

Pursley, J. R., R. W. Silcox, and M. C. Wiltbank. 1998. Effect of time of artificial insemination on pregnancy rates, calving rates, pregnancy loss, and gender ratio after synchronization of ovulation in lactating dairy cows. J. Dairy Sci. 81:2139-2144.

Rabiee, A. R., I. J. Lean, and M. A. Stevenson. 2005. Efficacy of Ovsynch program on reproductive performance in dairy cattle: A meta-analysis. J. Dairy Sci. 88:2754-2770.

Revah, I., and W. R. Butler. 1996. Prolonged dominance of follicles and reduced viability of bovine oocytes. J. Reprod. Fertil. 106:39-47.

Roche, J. R., N. C. Friggens, J. K. Kay, M. W. Fisher, K. J. Stafford, and D. P. Berry. 2009. Invited review: Body condition score and 
its association with dairy cow productivity, health, and welfare. J. Dairy Sci. 92:5769-5801.

Santos, J. E., H. M. Rutigliano, and M. F. Sa Filho. 2009. Risk factors for resumption of postpartum estrous cycles and embryonic survival in lactating dairy cows. Anim. Reprod. Sci. 110:207-221.

SAS Institute. 2006. SAS User's Guide: Statistics. SAS Inst. Inc., Cary, NC.

Silva, E., R. A. Sterry, and P. M. Fricke. 2007. Assessment of a practical method for identifying anovular dairy cows synchronized for first postpartum timed artificial insemination. J. Dairy Sci. 90:3255-3262.

Silva, E., R. A. Sterry, D. Kolb, N. Mathialagan, M. F. McGrath, J. M. Ballam, and P. M. Fricke. 2009. Effect of interval to resynchronization of ovulation on fertility of lactating Holstein cows when using transrectal ultrasonography or a pregnancy-associated glycoprotein enzyme-linked immunosorbent assay to diagnose pregnancy status. J. Dairy Sci. 92:3643-3650.

Souza, A. H., H. Ayres, R. M. Ferreira, and M. C. Wiltbank. 2008. A new presynchronization system (Double-Ovsynch) increases fertility at first postpartum timed AI in lactating dairy cows. Theriogenology 70:208-215.

Souza, A. H., A. Gümen, E. P. Silva, A. P. Cunha, J. N. Guenther, C M. Peto, D. Z. Caraviello, and M. C. Wiltbank. 2007. Supplementation with estradiol-17 $\beta$ before the last gonadotropin-releasing hormone injection of the Ovsynch protocol in lactating dairy cows. J. Dairy Sci. 90:4623-4634.
Thatcher, W. W., T. R. Bilby, J. A. Bartolome, F. Silvestre, C. R. Staples, and J. E. Santos. 2006. Strategies for improving fertility in the modern dairy cow. Theriogenology 65:30-44.

Vasconcelos, J. L., R. W. Silcox, G. J. Rosa, J. R. Pursley, and M. C. Wiltbank. 1999. Synchronization rate, size of the ovulatory follicle, and pregnancy rate after synchronization of ovulation beginning on different days of the estrous cycle in lactating dairy cows. Theriogenology 52:1067-1078.

Walsh, R. B., D. F. Kelton, T. F. Duffield, K. E. Leslie, J. S. Walton, and S. J. LeBlanc. 2007. Prevalence and risk factors for postpartum anovulatory condition in dairy cows. J. Dairy Sci. 90:315-324.

Wiltbank, M. C., P. D. Carvalho, A. Keskin, K. S. Hackbart, M. A. Meschiatti, M. R. Bastos, J. N. Guenther, A. B. Nascimento, M. M. Herlihy, M. C. Amundson, and A. H. Souza. 2011a. Effect of progesterone concentration during follicle development on subsequent ovulation, fertilization, and early embryo development in lactating dairy cows. Abstract no. 685 in Proc. 44th Annu. Mtg. Soc. Study Reprod., Portland, Oregon. Society for the Study of Reproduction, Madison, WI.

Wiltbank, M. C., R. Sartori, M. M. Herlihy, J. L. M. Vasconcelos, A. B. Nascimento, A. H. Souza, H. Ayres, A. P. Cunha, A. Keskin, J. N. Guenther, and A. Gümen. 2011b. Managing the dominant follicle in lactating dairy cows. Theriogenology 76:1568-1582. 